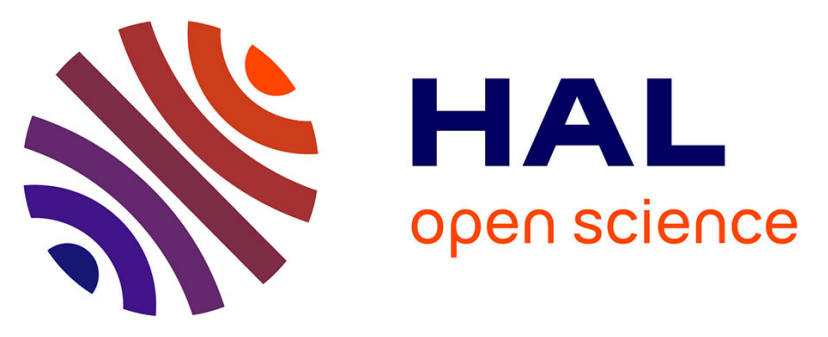

\title{
Students' Understanding of the Special Theory of Relativity and Design for a Guided Visit to a Science Museum
}

Jenaro Guisasola, Solbes Jordi, José-Ignacio Barragues, Maite Morentin, Antonio Moreno

\section{To cite this version:}

Jenaro Guisasola, Solbes Jordi, José-Ignacio Barragues, Maite Morentin, Antonio Moreno. Students' Understanding of the Special Theory of Relativity and Design for a Guided Visit to a Science Museum. International Journal of Science Education, 2009, 31 (15), pp.2085-2104. 10.1080/09500690802353536 . hal-00516746

\author{
HAL Id: hal-00516746 \\ https://hal.science/hal-00516746
}

Submitted on 11 Sep 2010

HAL is a multi-disciplinary open access archive for the deposit and dissemination of scientific research documents, whether they are published or not. The documents may come from teaching and research institutions in France or abroad, or from public or private research centers.
L'archive ouverte pluridisciplinaire HAL, est destinée au dépôt et à la diffusion de documents scientifiques de niveau recherche, publiés ou non, émanant des établissements d'enseignement et de recherche français ou étrangers, des laboratoires publics ou privés. 


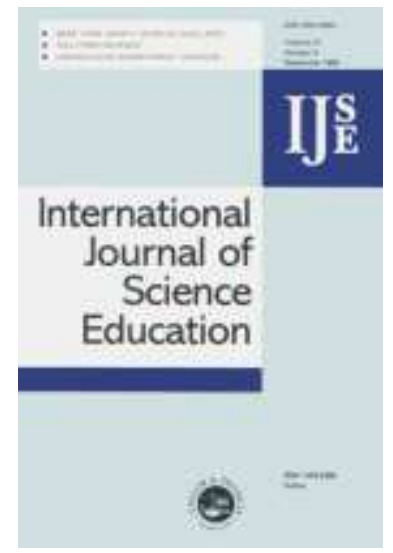

\section{Students' Understanding of the Special Theory of Relativity and Design for a Guided Visit to a Science Museum}

\begin{tabular}{|r|l|}
\hline Journal: & International Journal of Science Education \\
\hline Manuscript ID: & TSED-2007-0310.R2 \\
\hline Manuscript Type: & Research Paper \\
\hline Keywords: & physics education, misconception, learning activities, university \\
\hline Keywords (user): & $\begin{array}{l}\text { Theory of Special Relativity, Teaching materials design, Schools } \\
\text { visits to museum }\end{array}$ \\
\hline
\end{tabular}

\section{S) ScholaroNE" \\ Manuscript Central}




\section{Students' Understanding of the Special Theory of Relativity and Design for a Guided Visit to a Science Museum}

This paper describes the design of teaching materials that are used as learning tools in school visits to a science museum. An exhibition on the A century of the Special Theory of Relativity, in the Kutxaespacio Science Museum, in San Sebastian (Spain), was used to design a visit for first year engineering students at the university and assess the learning which was achieved. The first part of the paper presents the teaching sequence which was designed to build a bridge between formal teaching and the exhibition visit. The second part analyses the potential of the exhibition and the aforementioned teaching sequence to influence the students' knowledge of three aspects of the Special Theory of Relativity. The results obtained show that the design of the visit, with both pre-visit and follow up activities, was effective as a means of increasing students' understanding and stimulating their ability to argue scientifically.

Key words: Teaching materials design, School visits to Museums, Special Theory of Relativity

\section{Introduction}

In this paper we are going to describe the curricula design that are used as learning tool in school visits to a science museum. Learning in informal contexts and 'experience outside the classroom' is being recommended as an important element to promote interest in sciences and their learning and to encourage student motivation (Pedretti 2002). Visits to science museums represent one such type of these activities and they are used as part of the proposal to increase scientific literacy in both the student and the wider adult population. However, the results of research into the use of Science Museums as learning instruments for school children indicate that: a) teachers generally establish very general, or limited, objectives for the museum visit; mainly restricted to relating science to the social medium, or developing a practical science activity already undertaken in class (Griffin \& Symington 1997); b) Generally there is usually very little preparation for the visit and little monitoring of the actual visit in the museum, although the majority of research highlights the positive effects of good visit preparation on student learning and attitude (Gennaro 1981, Falk \& Dierking 2000); c) The importance of interaction between the students, and between students and the teacher, is highlighted (Hofstein \& Rosenfeld 1996).

Educators and researches are interested in how to develop the role of science museums in supporting school-based learning. This interest is illustrated by the increasing number of research projects on the interface between school curriculum and museums visits. Different studies have shown that visits to museums and science 
exhibitions, organised with activities to carry out during the visit and supported by appropriate prior and post visit activities to discuss in the classroom, can considerably increase student interest and knowledge (Anderson, Lucas and Ginns, 2000; Henriksen \& Jorde, 2001). Taking these findings into account, in this study we designed educational materials which were designed to improve learning in the School-Museum learning context and aim to incorporate the students' own questions, or topics, which have been previously analysed in class. This aims to ensure that students have an understanding of the information supplied by the Museum, within the previously decided parameters, and to promote critical analysis of the ideas resulting from the visit and the application of these ideas to new situations.

This paper looks at teaching the topic of the Special Theory of Relativity in a seminar for first year engineering students (students aged 18-19) which included a visit to the "A Century of the Special Theory of Relativity 1905-2005" exhibition. The exhibition was held in the Kutxaespacio Science Museum, in San Sebastian, with collaboration from the University of the Basque Country (Guisasola et al., 2005) and its objective was to provide intelligible and contextualised scientific information on the fundaments of the Special Theory of Relativity and its technological and social implications. The central topics of the exhibition were:

- The speed with which we can transmit information

- Reference systems: simultaneity of events and measuring time.

- The problem of the limit of the speed of light

- The origin of nuclear energy

The exhibition designers' intention was to help visitors, particularly groups of students over 15 years old, to use a scientific base to generate their own opinions and arguments related to topics in telecommunications and nuclear energy (Guisasola et al, 2005). The exhibition included computers simulations which visitors can manipulate, including a reconstruction of the famous experiment by Michelson \& Morley and explanatory panels. The panels use situations with which visitors are likely to be familiar with to capture their attention and they use analogies to explain the scientific principles.

This paper is centred on the design of the teaching sequence which uses visits to the exhibition "A Century of the Special Theory of Relativity 1905-2005" as part of n instructional approach which seeks to improve understanding of the Special Theory of Relativity. We tried to answer the following research questions: 
- What type of prior conceptions do the students have of the Special Theory of Relativity and its applications?

- How does the museum visit influence students understanding of the Special theory of Relativity and its applications? Does the students' understanding of this theory increase? Do students use more scientific arguments when discussing topics related to the Special theory of Relativity after visiting the exhibition?

The exhibition was the result of collaboration between a team of lectures from the University of the Basque Country (UPV) and the curators of the Museum. It is necessary to state that selection of the problems covered in the exhibition (mentioned in the previous paragraph) was proposed by the faculty team from the UPV. This selection of problems and contents was based on three criteria. Firstly, a description of the scientific context in which Einstein began his research and the scientific problems that he tackled, as well as the solutions (The Special Theory of Relativity) that he eventually devised. Secondly, an increase in interest and knowledge of the STR, centred on technological applications of the STR that can most impinge on the everyday life of ordinary citizens. Thirdly, upon the results of the investigation into students' alternative ideas about the STR.

This was not a standard exhibition put together by the Museum staff, nor was it outsourced to a company specialising in museum services, but rather a faculty team from the UPV, which conducts research into science education, had the opportunity to design the exhibition from the start, and conceived the content of the labelling, panels and the form of the presentation.

\section{Sample}

A total of 35 students ( $63 \%$ male and $37 \%$ female) in the first year engineering course participated in the experiment. These students study General Physics at university and they also studied physics for a year and a half after they graduated from secondary education. However, they have not covered the Special Theory of Relativity in any of the physics courses they have taken and nor is it planned that they will acquire knowledge on this topic within the course.

The students were chosen from a class given by a teacher who had worked on the "A Century of the Special Theory of Relativity 1905-2005" exhibition in the Kutxaespacio Science Museum. These students took a 4 hour seminar at university and 
visited the exhibition. As the experiment is not included in the official course programme, we can assume that the teacher was probably more than normally involved in motivating the students and presenting relevant activities.

\section{Teaching Sequence}

When designing the teaching sequence, we based it on the "contextual model of learning' by Falk and Dierking $(1992,2000)$ which incorporates many elements of what we know about learning. The model looks at multiple contexts, creating a useful framework to analyse the nature of learning, specifically in the non-school environment. It is emphasised that learning occurs in a context and that, in the absence of any external direction, each individual's associations can be insignificant. Learning is not an experience which is carried out in abstract, but in a specific situation in the real world; combining personal, socio-cultural and physical aspects. Visitors to a museum are considered as people who are actively involved in constructing and reconstructing knowledge. The model is intentionally more descriptive than predictive.

In the sequence which we are presenting a teaching unit has been designed and put into practice to act as a bridge between the school context and the museum context. For this purpose, activities were designed for 'before', 'during' and 'after' the visit, which provide a unifying sequence for the different contexts in which the students will learn. Furthermore, the type of activities has been designed taking into account the possibilities which are offered by each situation in school and in the museum. So, the pre and post visit activities are based more on analysing and discussing carefully selected situations involving STR, whilst the activities in the museum aim to provide students with an opportunity to experiment, provide meaning and interest to the questions raised, and let them search for information.

The teaching unit used as a research instrument in this work is summarised below.

\section{Pre-Visit Activities (2 hours)}

The teacher explains (10 minutes) that the objective of the seminar involves understanding the basis of the STR. Firstly, the students individually fill in a questionnaire on their understanding of STR and its social implications (30'). These topics are later covered in the pre-visit seminar. Once the questionnaire has been completed, a debate is started on the four situations which have been designed: 
"Telecommunications", "Your seconds are longer than mine", "Are muons young or old?" and "Experiment in the CERN". Different opinions are expressed on the situations which have been presented. The situations presented follow the sequence which will later be seen in the exhibition and which we can summarise in the following way:

- "Telecommunications": Is it possible to transmit information increasingly rapidly? Is this problem related to the Special Theory of Relativity?

- "Your seconds are longer than mine": Galileo and relative movement. Is it possible that a phenomenon lasts for a different time depending on where we observe it from? Is the speed of light of a torch faster in a high speed rocket than outside the rocket at rest?

- “Are muons young or old?": a practical example of different time measurements for the same phenomenon

- "Experiment in CERN": Does increasing the force applied to a body always give greater acceleration? What does the famous equation $\mathrm{E}=\mathrm{mc}^{2}$ mean? Does it have any relation to nuclear energy?

The first of the situations, introducing problems related to the speed of light and electromagnetic waves, is presented below.

\section{Story 1: Telecommunications}

Imagine a heart operation, or an organ transplant carried out between Osakidetza in Bilbao and a Hospital in Quito in Ecuador. For the operation to be successful, it is vital for the information to arrive via video conference (electromagnetic waves) in the shortest possible time and in the greatest possible quantity. This is not science fiction, in 2001 the first operation was carried out with transoceanic telesurgery. A team of experts from the European Telesurgery Institute in France carried out an operation from New York, on a 68 year old patient located in Strasbourg. Two surgeons drove the robots from New York, whilst the other two experts in Strasburg were in charge of controlling the computer system.

The information travelled $14,000 \mathrm{~km}$, from its point of origin in the United States to its destination in France. Due to the time which the information took to cover this distance and the coding period for the data on video, the movements of the surgeons appear on the TV monitors with a delay of 155 milliseconds, "a time which lies within the safety margins, which estimate 330 milliseconds as a maximum," said the team.

The electromagnetic waves which transport the information take a certain time to travel from one place to another. Also light, which is an electromagnetic wave, takes a certain time to travel from one point to another.

The possibilities provided by communication at increasing speeds are growing and we are already talking about a 'global world' and the enormous efficiency of new information technologies.

Do you believe that it is possible that the time will come when communication occurs instantaneously? Explain your opinion.

Students were organised into groups of four. They first read the information individually, and then discuss and answer the problem in groups. Before work-groups start answering the questions, the teacher explains, with examples, how evidence is used 
to support scientific explanations; they need to be able to evaluate evidence in terms of its adequacy, its relevance and its source. The teacher explains that, as will be seen in the visit to museum, scientific explanations can draw on a range of evidence; in the form of numerical data, recording of observations, or other established scientific facts, so there is a need to explore different ways to justify their ideas and conclusions.

When students are working in groups, the teacher takes a backseat, supervising the students, because students need time to think for themselves and to clarify their ideas. When the students have finished their work, there is a round table discussion, directed by the teacher. At the round table, each group must justify the answers that they arrive at. Ultimately, there will be one or several explanations for each problem. The teacher will insist that every explanation must be justified by evidence, or scientific arguments (Guisasola et al 2008).

\section{Visit to the Museum (1 hour 30')}

The visit took place two days after the pre-visit activities. The teacher and the students meet in the entrance hall and they are shown the different parts of the Museum on the map (rooms, panels, leisure areas, planetarium etc.). The teacher and the students walk together from the entrance hall to the exhibition room "A Century of The Special Theory of Relativity" of the Museum; the teacher asks them to look around and see the different ways in which information is given. They can see interactive panels, real experiments, computer simulations and multimedia presentations. The teacher reminds them about the work which they have done beforehand at university and how it can help them to centre themselves on the information which they want to obtain in order to resolve the questions posed in class. The students review the notes they took in the class discussion and the map of the exhibition.

The students divide themselves up into small work groups ( 4 people) which were established during the class discussion. One of the members of the group, who acts as secretary, carries a notebook and pencil - another member of the group could carry a video camera to illustrate the group's conclusions later. The students use a guide book designed to direct the students towards the information they need to look for in relation to the questions covered in the pre-visit activities. In the example we shown the process will be as follows:

Guide book (What has happened?) In the "controlling a robot from the Earth" simulation, read the panel information and then try to guide the robot to a certain point on a planet that has been chosen 
(Mercury, Venus or Mars). Does it take the same amount of time for the commands to reach the robot on each of the three planets? What determines the amount of time that it takes for the commands to reach the robot? Why do the commands take time to reach the robot?

Simulation panel: From Earth, you will command the movement of a robot on one of three planets that you choose: a) Mercury; b) Venus; c) Mars. Mercury is 82 million kilometres away from Earth, and light takes 2.2 minutes to cover this distance. Venus is 40 million kilometres away from Earth, and light takes 2,2 minutes to cover this distance. Mars is 56 million kilometres away from Earth, and light takes 3.1 minutes to cover this distance".

Exhibition information panel (located close to the simulation): Electromagnetic waves, which transport information, require time to travel from one point to another. Like any other electromagnetic wave, the speed of light in a vacuum travels at $300,000 \mathrm{Km} / \mathrm{s}$. Light therefore requires a certain amount of time to travel from one point to another, although due to its speed the distance must be very great in order to note it. As you can see from the simulation, at distances as great as those from Earth to Mars, commands sent from Earth Control Centre to the robot will take several minutes to arrive, and problems may arise when trying to control the robot.

Information transmission speed is key in the Communications and Information Society in which we live. Therefore, scientists and society have asked themselves: Is it possible to induce electromagnetic waves to travel faster than $300,000 \mathrm{Km} / \mathrm{s}$ ?

The students are free to move around the Exhibition. The teacher asks the students about the reasons for choosing one exhibit or another and how the work is progressing. The teacher moves between the different work groups showing interest in the students' activities, and asks them questions which stimulate them to look in greater depth at the information given by the panels and to answer the questions previously posed in class.

After about an hour, the students start to go to the Museum's leisure area for a 10 minutes break. They can chat with other groups there about the information which they have found and the progress they have made regarding the questions they brought with them. Then they will go back to the exhibition and programmed exhibits together to finish their research.

After one hour and a half the teacher reminds the group that it is time to return to the bus. The students will have been handling interactive exhibits and taking notes from informative panels or filling in their notebook. They are prepared to show the information they have found and answer any questions which emerge in the later session in the university.

\section{Post Visit Activities (2 hours)}

These activities were run in class in the week following the visit. In groups, the students reflected on the information and the experiences from the visit and whether their knowledge on the topic had changed regarding the pre-visit questionnaire. Later, 
they individually had to produce a final report which, among other questions, centred on the following aspects of STR:

a. Is it possible to transmit information at a speed which is greater than the speed of light? Have we reached the maximum speed for communications?

b. Can the same phenomenon last for different times depending on where it is observed from? Give an example and justify it.

c. Why is the speed of light the maximum possible in our universe? If we push an object with sufficient of force, couldn't we exceed this speed?

d. What is the relationship between mass and energy at very high speeds? Give an example and comment on it.

At the end of the session teacher takes the initiative in discussing and reformulating relevant information from the activities and experiments. In this process, students must propose well founded hypotheses and justify the approach which leads them towards a specific explanatory theory.

\section{Methodology}

It must be highlighted that the experimental design does not consist of the usual pre/post-test design, as the very instrument of research (the teaching unit) is part of the treatment. So then, a difference which is observed between the pre and post-test results, which is interpreted as a change in the students' understanding, cannot only be attributed to the visit to the museum, but rather to the overall pre-visit, visit and postvisit teaching process. The design of the experiment is based on results from other research into teaching/learning sciences in non formal contexts, which indicates the need to make bridges between the school curriculum and visits to museums (Falk, 1997).

The students' written answers to the questionnaires and reports were analysed qualitatively, taking as references answer categories which were shown in other previous research (Gil \& Solbes, 1993; Ramada et al., 1996; Villani \& Arruda, 1998) which were clarified and reformulated during the process (Ericsson \& Simon, 1984; Kvale, 1996). Common tendencies have been identified in the students' answers and representative examples of their answers have been included here.

This study has built on Jiménez-Alexandre et al.'s interpretation of Toulmin's Arguments Pattern (TAP) (Toulmin 1958) using framework (Jiménez-Alexandre et al 
2000, Jiménez-Alexxandre and Pereiro-Munaz 2002,2005) to analyse argumentation that occurs as students engage in decision making activities in pre and post-visit sessions. The analysis will help to determine how the students use evidence to support explanations and the quality of their argumentation.

\section{Students' Knowledge of the Special Theory of Relativity and its Applications}

One of the research questions within this paper aims to identify students' knowledge of and attitudes towards Special Theory of Relativity (STR). In this section we will present some of the students' conceptions. All the conceptions presented are those shown by a minimum of 10 students.

In the case of the STR, the students found themselves in a new situation, which was not intuitive and not very predictable. The process of understanding this theory usually generates some anxiety, as they cannot usually draw on everyday experiences to accept its plausibility, or corroborate its efficiency (Alemañ, 1997; Pérez \& Solbes, 2003; Toledo, Arriasseco and Santos, 1997). In formal teaching, different studies highlight secondary school students' (14-18 years old) difficulties in acquiring an abstract vision of the concepts of space and time, which are differentiated from the explanations limited by perception and absolute reference frameworks (Castells \& Pinto, 2001; Saltiel \& Malgrane, 1980). Also for first year engineering students, analysing the movement from a reference system outside oneself is something which is only achieved with quite a lot of training (Galili \& Kaplan 1997).

The relationship between mass and energy is treated by students as a mere relationship between magnitudes, ignoring its equivalency, or without establishing a relation between them. Students are not usually capable of reasoning appropriately on energy in nuclear fission processes. Also, students do not usually know about the applications of STR and they consistently indicate that this knowledge has scarce value for them and for science.

In this paper, the most common trends in students' knowledge of STR and its applications are shown in table 1.

Table 1. Student' knowledge detected in the pre-visit questionnaire

\section{Conceptions}

\section{Example answers}

\section{(Number of reports, $\mathrm{n}=35$ )}

1. The theory is considered to be unrelated to everyday experience $(n=10)$ and they confess that they do not know the theory, or they do not answer $(n=17)$

1. "I don't know what the theory is specifically about, a lot of people talk about it, but nobody says what it is exactly. I think that it is applied in questions relating to space trips..." 
2. Only $15(43 \%)$ students mention between 1 and 3 applications of the theory (10 space exploration, 7 nuclear energy, 2 lasers and 2 atomic bombs)

3. Notion that communications could one day be instantaneous (there is no limit for the speed of communications) $(\mathrm{n}=23)$.

4. Confusion between reference systems and bodies in movement $(n=20)$, when they have to explain that the same phenomenon can last for different times.

5. When they are asked to explain the meaning of the equation $\mathrm{E}=\mathrm{mc}^{2}$ in words, $65 \%(\mathrm{n}=23)$ make superficial descriptions of the formula and only 5 students give a physical meaning.
2. "It is applied to obtain nuclear energy; either in the form of an atomic bomb, or as a source of energy. In the study of space, black holes, etc."

3. "Communications will one day become instantaneous; they are not right now because of technical problems which will be overcome in the future."

4. "...if two clocks located in reference systems which move at different speeds mark different times, this is due to the fact that speed depends on space and time. Depending on the speed the body is moving, the body will take different amounts of time..."

5."... Kinetic energy is equal to the mass of the body, multiplied by the speed it is moving at squared."

The vast majority of the students confessed their ignorance of STR and they confirmed it when they were asked about the meaning of the equation $\mathrm{E}=\mathrm{mc}^{2}$ (item 4 on the questionnaire). In this item, they are asked to explain the following statement: "Einstein states that when the total force on a body increases, the acceleration of this body does not always increase." The majority of the students reason, in accordance with Newton's Second Law from classical physics, that Einstein's statement does not make any sense to them.

This same ignorance is reflected when enquiring into their knowledge of its applications. Only a minority of students could indicate an application. This result is consistent with the vision that they have of STR, as something which is not related to everyday life (Pérez, 2003).

The majority of students had never wondered about a limit for the speed of light, or electromagnetic waves. This result is consistent with studies which indicate that the teaching of optics and kinematics does not cover problems related to measuring the speed of light and its epistemological relevance (Villani \& Arruda, 1998).

They do not know how to distinguish between a reference system and a moving body and consequently they do not understand what it means to measure time in reference systems which move at different speeds. This result coincides with several studies which indicate student difficulties in understanding the meaning of Inertial 


\section{The Exhibition's and Teaching Materials' Potential to Influence Students' Knowledge}

The second research question covers the exhibition's potential, in combination with the pre and post-visit treatment in the classroom, to influence the students' understanding of STR.

Firstly, we are referring to the question of whether suitable design combined with the visit to a museum can increase understanding of the scientific principles. The majority of students explicitly indicate in their post-visit report that their knowledge of the Special Theory of Relativity and its applications has increased:

\section{Example}

...the visit to the exhibition has helped me to understand why the speed of light in a vacuum is the maximum it can achieve. I didn't think that the Theory of Relativity covered this question. I was surprised by the simulation which justifies that the same clock can mark different times in different reference systems. Furthermore, I have seen interesting applications, such as the muons and radioactive elements...

From the students' comments it seems that we can deduce that there is a subjective conviction that they have discovered new information and experiences which have helped them to understand some aspects of relativity better. The students express a better understanding of the STR's social use.

One interesting question was to find out if some of the students' preconceptions, or distorted ideas, had modified as a result of the seminar and visit. Categorising and 
analysing the students' pre-visit questionnaires and comparing them to the post-visit reports show differences in some areas that were highlighted in the seminar-visit.

It is difficult to evaluate adequately all the answers given by the students. In order to characterise the responses, the comments recognised as "an explanation" (Cortazzi, 1993) were coded for occurrence of some easily recognizable features, such as: alternative conceptions, scientific statements and argumentation from a scientific point of view . For example, in the first question of questionnaire (see annexe), if the student's explanation has one or more scientific statements, which include justification based on evidence, the answer was considered as correct and it was included in the 'correct' category shown by the grey columns ( pre-visit) and black columns (post-visit) from figure 1 . When the answers have any alternative conceptions or the statements are not justified, they are not included in the 'correct' category.

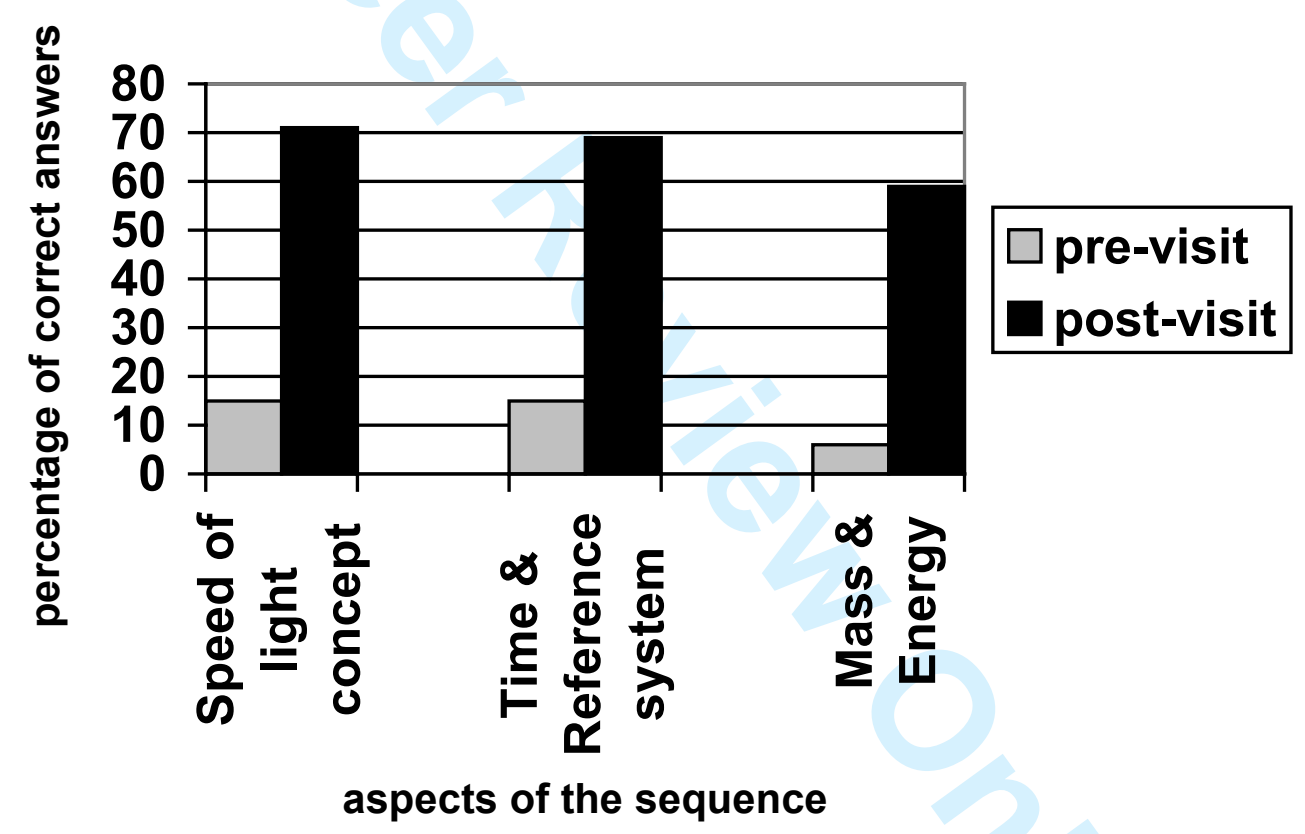

Figure 1. The grey columns indicates the proportion of pre-visit reports in which students explain correctly. The black columns indicates the proportion of post-visit reports in which students explain correctly. The first aspect of the STR contemplated in the exhibition deals with the understanding of "The speed of light has a limit and is constant". The second one "They comprehensively understand that the same phenomenon can last different times depending on the reference system". The third one "They understand the equation $\mathrm{E}=\mathrm{mc}^{2}$ qualitatively".

When students explain question related with the first aspect "The speed of light has a limit and is constant", they use three types of correct explanations: a) Factually using the experiment by Michelson \& Morley (47\%); b) Qualitatively using the example of the "rocket and the torch" in the exhibition $(34 \%)$; c) Using the time 
Michelson and Morley used the speed of rotation of the Earth round the Sun to launch a ray of light in the direction of the movement and another ray perpendicularly. When they did the experiment, they saw that the two rays took the same time to cover a determined distance. So it was concluded that the speed of light is constant in any chosen reference system and in a vacuum, never greater than $300,000 \mathrm{Km} / \mathrm{s}$.... If we look at the example from the exhibition, what Michelson and Morley saw was that the speed of light emitted by the torch was the same when it was a rest as when it was emitted from the rocket.

(report group 4)

Group 4 made the claim that the speed of light is constant and it has a limit and the data to which they referred to came from "the Michelson and Morley experiment". A warrant for this argument might be the explanation of what Michelson and Morley's experiment shows.

Further support can come from backings that lend authority to the warrant. For example, the equations from the exhibition appear in all the reports, with justifications based on the Special Theory of Relativity:

Because when the speed is very high, similar to the speed of light, Einstein indicated that the Galilean transformation breaks down. In the case of the torch and the rocket, it does make sense that the speed of the torch is: $v_{l u z}=c+v_{\text {cohete }}$, but in accordance with Einstein's equation, if we suppose that the speed of the rocket is 0.9c, we have: $v_{l u z}=\frac{0,9 c+c}{1+\frac{0,9 c^{2}}{c^{2}}}=\frac{1,9 c^{3}}{1,9 c^{2}}=c$ (Group 6)

However, around $30 \%$ of students affirm that it is not possible to instantaneously transmit information. They do not justify the limited speed of light. These students use the exhibition information, but their explanations do not contain the elements of argumentation. For example:

... if the information has to cover great distances, it cannot be instantaneous as electromagnetic waves (light) must take some time and have limited speed...(Group 3) 
Regarding the second aspect (the same phenomenon can last different times depending on the reference system), when looking at measuring the different intervals of time for the same phenomenon according to the chosen reference system, around half of the reports use justifications following the lines of the theory; explaining the example on the average life of the muons and the number which reach the surface of the Earth, which was described in the "Time" simulation in the exhibition:

This difference in time measurement for bodies close to the speed of light allows us to explain why large quantities of muons are detected at the Earth's surface without having disintegrated on their journey. (Group 9)

The report states that the same phenomenon can last different times depending on the frame of reference and the data which they use to support this comes from the "Time" simulation of the exhibition. The support for this argument is the explanation for why a lot of muons are detected on the Earth's surface.

In reference to the third aspect (mass and energy), the relationship between mass and energy expressed by Einstein's famous equation, there are three different types of correct explanations: a) Using the CERN simulation in the exhibition (31\%); b) Qualitatively differentiating between mass at rest and mass at high speeds (31\%); c) Qualitatively reasoning about the impossibility of obtaining greater acceleration when more force is applied (38\%).

An example of the first type of explanation is the following:

In the "energy" simulation we saw, in the CERN laboratory, that when particles obtain great speeds the mass and energy are equivalent and produce new particles...(Group 11)

The claim that energy and mass are equivalent and the data which they used comes from the "energy" simulation. However, there is not an explanation to support as a warrant of the argument.

Examples that do not use evidence and that the explanation is based in an incorrect reasoning of the formula, are the following:

Einstein's equation tells us that mass and energy are equivalent. When a body is moving at high speeds, the energy which it has it can be transformed into mass and vice-versa; a reduction of mass can be associated with an intense emission of energy, given by $\mathrm{E}=$ (mass loss) $\mathrm{c}^{2} .($ Group 8$)$

A body's inertia becomes enormous when it is moving at speeds close to the speed of light, so that no matter how much energy we use, we will not manage to increase its speed.... This fact shows us that the mass of an object increases with its speed, meaning that there is a relationship between the mass and the object's kinetic energy. Einstein showed this relationship in his famous equation. (Group 11) 
The supporting argument used is based on an incorrect idea that mass varies with speed. The widespread nature of the misconception that mass varies with speed is supported by many different research studies (Alemañ 1997, Pérez and Solbes 2003). This could be due to the fact that traditional teaching introduces concepts, such as relativistic mass, which are now outdated. The concept of the 'relativistic mass' appears in more than $80 \%$ of Spanish physics texts in the final year at secondary school, with very different and contradictory focuses on their meaning (Pérez and Solbes 2006). However, current consensus only uses mass at rest, or unvarying mass, and many general physics books which used relativistic mass in previous editions now no longer do so. Einstein, working from the introduction to space-time by Minkowski, categorically, did not recommend the use of mass depending on the speed:

"It is not good to introduce the concept of mass $\mathrm{M}=\mathrm{m} /\left(1-\mathrm{v}^{2} / \mathrm{c}^{2}\right)^{1 / 2}$ of a moving body as it is not a clear definition. It is better not to introduce another mass concept other than 'mass at rest' m. Instead of introducing $\mathrm{M}$, it is best to mention the expression of the moment and the energy of a moving body" (quoted by Okum, 1989).

It should be mentioned that around $50 \%$ of the post-visit reports, in one or in all of the three aspects considered, do not use the new data which the exhibition provides; maybe because both the theory itself, and the data that support it were not well understood by students.

Also, about $50 \%$ of post-visit reports, in one or all of the aspects, do not contain the main characteristic elements of argumentation, as cited in TAP (Toulmin 1958). A great difference is seen in the use of scientific argumentation (see figure 2). The difficulty students have in arguing from a scientific stand point is also seen in the results from Brickhouse et al. (2006) with university students studying in the second year of an astronomy degree. They also found that students had more difficulties in justifying their explanations and using data to support their arguments when dealing with relativity than other subject areas in the course. 


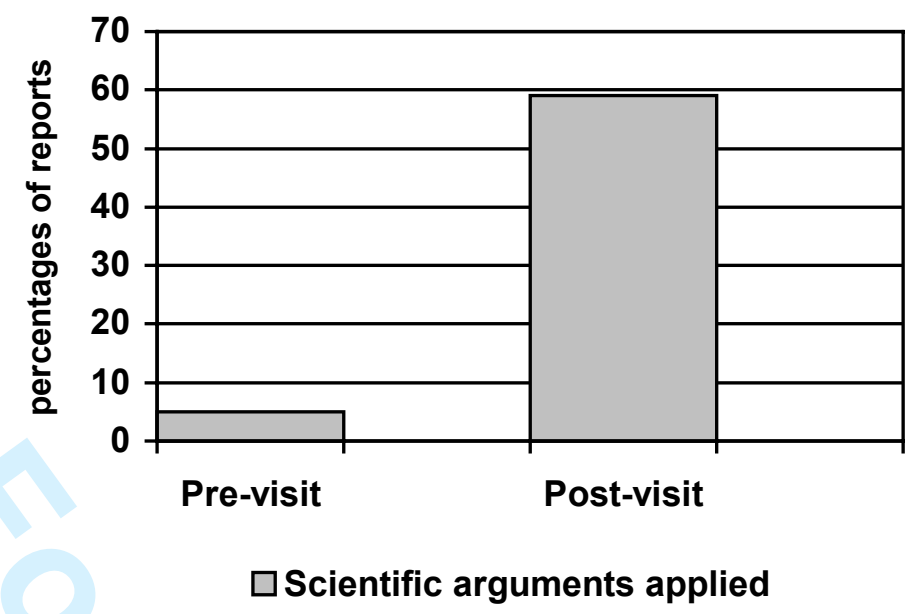

Figure 2. The columns indicate the proportion of the students' reports in which at least 2 or 3 aspects considered in the exhibition are argued scientifically, before and after visiting the Museums.

Although the students on the first year engineering course have not received prior instruction on STR, they have greater scientific knowledge than the average citizen. However, scientific argument was rarely used in the pre-visit questionnaire to support the statements they made. Also, in Spanish University classes, it is not usual for students to have the opportunity to argue and justify their ideas scientifically (Guisasola et al. 2003). However, in this piece of research, it has been shown that when the students are given information and appropriate questions to discuss, there is a significant increase in the use of scientific reasoning to defend their ideas.

Whilst student understanding clearly appears to have improved, the students do not always use the information they are given to develop the knowledge targeted by the exhibition designers. In the simulations and the panels which explained Einstein's famous equation, the students identify the equivalency between mass and energy:

The formula $\mathrm{E}=\mathrm{mc}^{2}$ tells us that the mass and the energy are the same. (Group 6)

The formula $\mathrm{E}=\mathrm{mc}^{2}$ permits us to obtain nuclear energy as the mass and energy are equal. (Group 7)

In other panels and simulations which the recounted Einstein's thought experiment on clocks and measuring time in different reference systems, the students had to understand the counteraction or lengthening of the time in different reference systems. However, many students concluded:

It seems that the clocks at rest and in the train measure different times for the same fact, but this is only one explanation; I don't think it really happened... 
Einstein's formula of time equivalence gives, as a result, different time measurements, but this is difficult to believe. I do not think that the time 'really' gets longer or shorter...

These answers correlate with other studies where it is shown that students do not reason effectively in terms of space-time properties; their minds requiring fixed properties (the distances measured are independent of the reference system, Villani \& Pacca, 1987) and three-dimensional bodies, rather than points, for a realistic vision of nature (Gil and Solbes, 1993). The student admits that different observers "seem" to obtain different measurements, but "really" there is only one measurement of space, time or the speed of light. Hewson (1982) showed how even the teachers themselves found it difficult to change this inaccurate concept of absolute space and time.

These erroneous answers, and other unexpected answers, show that inviting visitors to the exhibition, with the aim of getting them to integrate the information from the panels and simulations and thus form their own opinion and conclusions, does not always have the desired effect. In this research, due to the chosen theoretical framework, it was clear that the students' preconceptions on relativity would influence their interpretation of the exhibition. Also, the last two examples show that students incorporate the new scientific knowledge along with other types of knowledge, on epistemological and moral values, to form an opinion on a scientific theory and it relationship with society. So, the students take on and use the scientific explanation that the clocks can mark different times in different reference systems: "It seems that the clocks at rest and in the train measure different times for the same fact," "Einstein's formula of time equivalence gives different time measurements as a result and the "muon" simulation provided evidence for the theory."

The students made the claim that clocks at rest and in movement measure different time for the same event and they provide data from "the muon" simulation. Einstein' formula is used to backup the supporting argument. However, they do not incorporate the explanation into their system of beliefs: "I do not think that it really happens," "I don't believe that the time 'really' gets longer or shorter..."

In order to investigate the effects of the Seminar on students' attitude and interest to STR we analysed the last question of the sequence: What did you learn from the seminar? Many students gave more than one explanation, but the vast majority of students believed that they were now (more) aware of the practical applications of the STR and they noticed that this theory was interesting for human development and the every day life. We scored the students' perception of the usefulness of the Seminar and 
their interest in the STR, measuring the percentage of reports which included 3 or more applications of the Special Theory of Relativity; before and after the visit respectively. The results are shown in figure 3.

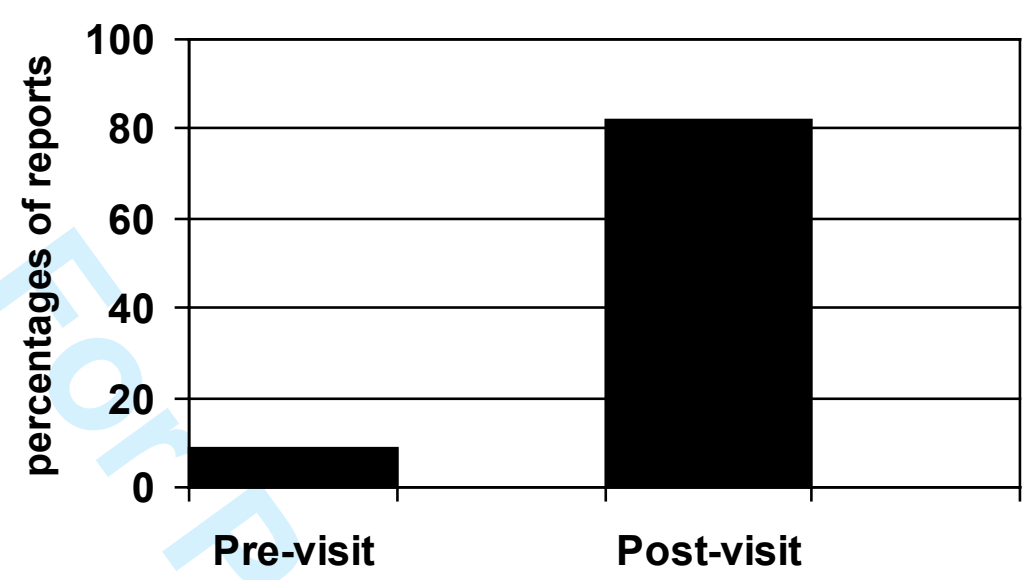

Applications

Figure 3. The columns indicate the proportion of reports which mention 3 or more scientifictechnical applications, with social implications, of the Special Theory of Relativity, before and after the visit respectively.

We also gathered information from informal talks to students after the visit to museum. Some students said that it was nice to have this type of Seminar as a complement of their learning. They also asked for more of this type of activity, even in place of regular teaching.

\section{Educational Implications}

The results obtained have a number of practical implications for designing teaching sequences which use visits to science museums as a part of the teaching approach.

A teaching sequence has been designed for this study in order to integrate the visit to an exhibition on STR into what is happening in the classroom. In accordance with the theoretical framework proposed by Falk and Dierking $(1992,2000)$ the teaching sequence consists of three phases ('before', 'during' and 'after'). It should be noted that the pre-visit design, which includes activities and 'situations' that tie into the contents and objectives of the exhibition, requires a profound knowledge of the same on the part of the sequence designers. In the case that we present, the designers of the 
teaching unit had participated in organising the exhibition, which provided a natural take-off point for designing the different sequential phases.

Likewise, the school session activities have a dual objective; both informing the students of the content and objectives of the exhibition, and stimulating the students into scientifically arguing their explanations and to thinking about the problems related to scientific knowledge. This starting point has been shown to be useful when 'guiding' the search for information in the exhibition and analysing the information.

Another important element in the organisation of information in the teaching sequence has been the knowledge of the difficulties that students have in learning about the STR. Research into misunderstandings in physics has shown that these misunderstandings are similar in different countries and throughout the school age range. Museum education specialists, teachers and designers of sequences of school visits to museums must find out visitors' possible misunderstandings in relation to the topics covered in their exhibitions, as these can interfere in the information transmission process and the process of building scientific knowledge, which they aim to achieve.

The results show that the teaching sequence and exhibition visit have increased the students' interest, knowledge and understanding of the Special Theory of Relativity and its applications. Likewise, after the plenary session the majority of students can adequately prove that the speed of light is constant and that it has a limit. However, meaningful learning of other aspects of STR, such as that the same phenomenon can last different times depending on the reference system, or the qualitative relation between mass and energy at high speeds, has presented more difficulties and only a minority of students show a correct understanding. This may be due to the fact that a deeper knowledge of the concepts of the STR could require a sequence having more discussion, more sessions, and that would include a second visit to the exhibition.

It should be highlighted that only around half the students involved in this study have shown the ability to argue and scientifically justify their ideas and their assessments of STR. This could be due to the students not being used to arguing their ideas from a scientific standpoint and justifying their opinions within science classes. Providing students with experience, along with information, so that they can express their reasoned opinions on scientific theories and their corresponding applications, is one of the main components of scientific education. When school visit programmes are designed for museums, special care must be taken with the aspects which relate information on scientific concepts with scientific argumentation. 
In this research, the teacher who took part in the experiment participated in designing and developing the exhibition, and so the designers of the teaching unit had a deep knowledge of the content and objectives of the exhibition. This is a great help in designing and implementing a teaching sequence to integrate a museum visit into classroom study. However, this will not usually be the case, but we think it is necessary for teachers or teams of teachers to be informed about the contents and objectives of the exhibitions prior to designing their teaching sequences. It is necessary to take into account the objectives of the exhibition and those of the curricula, in designing teaching sequences as a bridge between the exhibition and school-based learning.

\section{Bibliography}

Allen, S. (2004). Designs for learning: Studying science museum exhibits that do more than entertain. Science Education, 88, S17-S33.

Alemañ, R. (1997). Errores comunes sobre relatividad entre los profesores de enseñanza secundaria. Enseñanza de las Ciencias, 15(3), 301-307.

Anderson D., Lucas K.B., \& Ginns I.S. (2000). Development of knowledge about electricity and magnetism during a visit to a science museum and related post-visit activities. Science Education, 84, 658-679.

Brickhouse N.W., Dagher Z.R., Shipman H.L., \& Letts W.J. (2006). Why thing fall: evidence and warrants for belief in a college astronomy course. In R. Millar, J. Leach \& J. Osborne (eds) Improving Science Education, the contribution of research (pp. 11-26). Buckingham, UK: Open University Press.

Castells, M., \& Pinto, R. (2001). Students' reasoning strategies in solving qualitative problems of Galilean relativity. In R. Pinto \& S. Surinach (Eds.), Physics Teacher Education Beyond 2000 (pp. 423-427). París: Elsevier.

Cortazzi, M. (1993). Narrative Analysis. London: Palmer Press.

Doménech J.L., Gil-Perez D., Gras-Martí A., Guisasola J., Martínez-Torregrosa J., Salinas J., Trumper R., Valdés P., \& Vilches A. (2007). Teaching of energy issues: A debate proposal for a global reorientation. Science \& Education 16, 43-64.

Ericsson, K.A., \& Simon H.A. (1984). Protocol analysi : verbal reports as data . Cambridge: MIT Press.

Falk, J.H. (1997). Testing a museum exhibition design assumption: Effect of explicit labelling of exhibit cluster on visitor concept development. Science Education 81, 679-687.

Falk, J.H., \& Dierking L.D. (1992). The museum experience. Washington DC: Whalesback Books.

Falk, J.H., \& Dierking L.D. (2000). Learning from museums. Visitor experiences and the making of meaning. New York: Altamira Press.

Galili I., \& Kaplan D. (1997). Extending the application of the relativity principle: some pedagogical advantages. American Journal of Physics 65(4), 328-335.

Gennaro E.D. 1981. The effectiveness of using previsit instructional materials on learning for a museum field trip experience, Journal of Research in Science Teaching 18(3), 275-279

Gil D., \& Solbes J. (1993). The introduction of modern physics: overcoming a deformed vision of science. International Journal of science Education 15(3), 255-260.

Griffin J. \& Symington D. 1997. Moving from task-oriented to learning-oriented strategies on school excursions to museums, Science education 81(6), 763-779

Guisasola J., Furió C., Ceberio M., \& Zubimendi J.L. (2003). ¿Es necesaria la enseñanza de contenidos procedimentales en cursos introductorios de física en la universidad?, Enseñanza de las Ciencias Extra, $17-28$.

Guisasola J. Furió C. \& Ceberio, M. (2008). Science Education based on developing guided research. In M.V. Thomase(Ed.) Science Education in Focus. Nova Science Publisher (in Press).

Guisasola J, Peñalba M., Barragués J.I., Moreno A., \& Ares F. (2005). ¿Con qué rapidez podemos transmitir la información?. Centenario de la Teoría Espacial de la Relatividad 1905-2005,. On line http://www.miramon.org/icons/imgpc/kutxaespacio/pdfs/guias_didacticas/GUIA_EINSTEIN.pdf, (accessed September 2007). 


\section{Annexe. PRE-VISIT QUESTIONNAIRE FROM THE TEACHING UNIT}

1. The possibilities provided by communication at increasing speeds are growing and we are already talking about a 'global world' and the enormous efficiency of new information technologies. Do you believe that it is possible that the time will come when communications occur instantaneously?

2. This year, World Physics Year is being held to coincide with the Centenary of Albert Einstein publishing the "Special Theory of Relativity" in 1905. What benefits has this theory brought to society? Give three practical applications.

3. One of the most famous statements of Albert Einstein's Theory of Relativity is that two clocks situated in reference systems which move at different speeds mark different times. How would you explain this to your little brother or sister with an example? 
4. According to the American magazine TIME, the most famous equation of the 20th century is: " $E=$ $\mathrm{mc}^{2}$ " Could you explain in words, not formula, what this equation means? Give an example of the application of this equation. 